\title{
An Aggregate Economy with Different Size Houses*
}

\author{
José-Víctor Ríos-Rull \\ University of Pennsylvania, \\ CAERP, CEPR, NBER \\ Virginia Sánchez-Marcos \\ Universidad de Cantabria and Fedea \\ September 2006
}

\begin{abstract}
We build an aggregate model with different size houses and liquid assets. Typical households are born, are subject to idiosyncratic earnings risk and save for both life cycle reasons and housing reasons. Typically, a subset of these households, after accumulating some assets, put a down payment and buy a small, starter's, house or flat. As time passes, some households upgrade to a larger and nicer house. Households with houses may also eventually downgrade to a flat or even to no house and flat owners may sell. Our specification attempts to replicate some important features of modern aggregate economies: The distribution of earnings and
\end{abstract}

*This paper was prepared for the 2006 Summer Meetings of the European Economic Association. V. Sánchez-Marcos is thankful for research funding from the Spanish Ministry of Science and Technology, project SEJ 2006-10827/ECON. 
of housing and non-housing wealth as well as some macroeconomic aggregates, including features of the mortgage issuing sector.

Keywords: Housing, Macroeconomics, Calibration 


\section{Introduction}

There is a tradition of work in modern macroeconomics using models with a large number of households subject to idiosyncratic earnings shocks where savings are used to smooth consumption across time (see Aiyagari (1994), Castañeda, Díaz-Giménez and Ríos-Rull (1998) and Krusell and Smith (1997) to cite a few). This work has studied the determinants of wealth inequality as the outcome of uninsurable income shocks where households have access to a perfectly liquid asset that is used to smooth consumption across time. In the model economies of this type households are continually adjusting their asset level. In this paper we extend this work to environments where there are various assets, financial assets that are perfectly divisible and can be costless adjusted and other assets that come in predetermined but quite large sizes, that can be traded only at a considerable cost, that can be partially purchased on credit, and that give the owner some advantages (due perhaps to the tax system or to moral hazard reasons). We take these assets to be houses.

The specific aim of hour work is to build blocks for the study of asset price changes. In this regard, an important specificity of our work that departs from standard macroeconomic models is that the stock of assets is not capital which is essentially lagged output. Instead, we take the 
opposite extreme and model the stock of assets as Lucas trees that are in limited supply and where the model determines their prices instead of their quantities. As we will see, this structure is equally well posed as the standard growth model to map to a modern aggregate economy. There are several paper in the literature related to us. Gruber and Martin (2003) study an economy with illiquid durable consumption goods. They show that the decision rules display areas of inaction, and that financial wealth displays more dispersion than wealth held in the form of consumer durables. They also compare economies with identical parameterizations varying transaction costs (finding that higher transaction costs yield more savings) and the relative size of down payments (the bigger the down payment the higher savings). Martin (2005) is quite an interesting paper that explores in the context of a representative household model what are the implications of changes in characteristics over time (like those matching some of the demographics of the last half century) for asset prices, in particular housing prices, and interest rates. Ortalo and Rady (2006) is a slightly different paper that made interesting claims about the possibility of chain effects in the changes of the price of houses of different sizes due to the multiplying effects of capital gains -small changes in the price of small houses induce large increases in the equity of their highly leveraged owners that 
may want to switch to larger houses pushing their prices even further. In a way our work aims in part to find out the quantitative possibility of this channel if any. Nakajima (2005) studies the response of of housing prices to an increase in the volatility of individual earnings and finds that the level of housing prices moves quite a bit in response to what is a pure second moment change without any change in the level of economic activity. Davis and Heathcote (2005) is interested in the business cycle properties of housing construction, but they worry about housing quantities not prices. Díaz and Puch (2005) documents how the properties of model economies relate to the down payment requirements. Chambers, Garriga and Schlagenhauf (2005) connects the increase in housing ownership to reductions in the down payment. Finally, Díaz and Luengo-Prado (2004) studies the determinants of housing tenure choice. There are other papers that also work on housing prices, but there notion of houses lacks some of the features that we think are more crucial to capture their essence, namely that they are big relative to its purchasers finances, that they are very costly to buy and sell, and that they provide an advantage to the owner that prevents the appearance of a rental market as a good substitute of ownership. A fourth feature, is, we think, new, that we both have different sizes and that houses cannot be built from scratch, in fact ours is more a model of hosing 
lots rather than a model of structures.

In particular, our work is closely related to Gruber and Martin (2003) and to Díaz and Luengo-Prado (2004) and we have slightly different calibration properties. For example we manage to get a larger group of people with no housing; but our wealth Gini Index while being closer to that in the data than the former paper is further than the one in the latter paper; we generate too much indebtedness and this two paper too little. So what is our value added? First, we are building the blocks of a structure capable of addressing price changes by having a finite number of housing (or perhaps better of lots) sizes and what is more important, units since we have an economy of the Lucas trees variety. Second, we are interested in the dynamics of the purchases and upgrades of houses and in this regard we provide information of effective down payments of first and repeated home buyers. Third, our structure is designed to be expanded in the direction of aggregate uncertainty and we give some information of how to do this, which is a challenge both theoretically and computationally.

\section{The Stationary model economy}

The model economy analyzed in this article is a modified version of a Lucas trees' economy with uninsured idiosyncratic risk and in this version no aggregate uncertainty (although it is lurking at the end of 
the tunnel). Until we say otherwise we are only looking at stationary equilibrium. The key features of our model economy are the following: (i) it includes a large number of households that die exponentially, have identical preferences and face an uninsured, household-specific shock to their endowments of efficiency labor units; ${ }^{1}$ (ii) there are three type of assets in fixed supply (Lucas trees) in the economy, a standard type of tree with a constant dividend in terms of the consumption good that we label bond, and two other types of trees (houses and flats) that provide their holders with a utility shift that we take to be dwellings. Trades of the standard tree do not require resources and can be done in any size while trades of the dwellings are expensive and each household can hold at most one dwelling which comes in a fixed size.

Preferences and Shocks Households are born and die exponentially with probability $\pi$. Preferences are given by $u_{d}(c)$ where $d$ indicates the type of dwelling a household may be associated with and that can be either none, a flat or a house, $d \in\{0, f, h\}$. Houses are better than flats which is better than nothing $u_{h}(c)>u_{f}(c)>u_{0}(c)$. Individuals are heterogeneous in their earnings ability that is uncertain. We consider 3 different earnings groups so that we reproduce observed earnings

\footnotetext{
${ }^{1}$ Actually there is also population growth but we abstract from it in the presentation of the model to reduce the burden of notation.
} 
inequality. The earnings group of each individual evolves according to a Markov process. Furthermore, individuals face another uninsurable shocks to earnings. Households subject to earnings shocks $\epsilon$ drawn from $F(\epsilon, e)$ with $e \sim \Gamma_{e e^{\prime}}$ and

$$
F(\epsilon, e)=\left[\frac{\epsilon-\underline{\epsilon}}{\bar{\epsilon}-\underline{\epsilon}}\right]^{\chi}
$$

Markets There are various markets in this economy. There are spot labor market that (essentially irrelevant), and bonds and dwellings markets, are traded also in spot markets at prices $\left\{p_{\ell}, p_{f}, p_{h}\right\}$ respectively. There is also an annuity market so that no assets disappear. This means that the assets of the dead are share proportionally by the holders of that asset.

There are borrowing constraints and dwellings can be used as collateral. Individuals can borrow a fraction $1-\alpha$ of dwellings value. Dwellings are traded with costs that we pose on the buyer and that we write as $\phi\left(d, d^{\prime}\right)=p_{d^{\prime}}(1+\delta)$ if $d=0$ and $\phi\left(d, d^{\prime}\right)=p_{d^{\prime}}(1+\delta)-p_{d}$ otherwise.

Household's Problem To write the problem of household in a convenient way given that it is non concave we use two different functions. Function $V_{e, d}(y)$ denotes the value function of an household that belongs to an earnings class $e$, has dwelling $d$ and financial savings $y$ before the realization of the earnings shock $\epsilon$ and after realization of the earning 
class shock $e$. Function $W_{e, d}(a)$ is the value function of a household in earnings class $e$, has dwelling $d$ and cash in hand $a$. Consequently their relation is

$$
V_{e, d}(y)=\int_{\epsilon} W_{e, d}\left[\left(p_{l}+r\right) y+\epsilon\right] F(d \epsilon, e)
$$

Furthermore, denote by $W_{e, d}^{d^{\prime}}(a)$ the maximal utility of an household that belongs to earnings class $e$, starts the period with dwelling $d$, has dwelling tomorrow $d^{\prime}$ and has cash in hand $a$. Consequently,

$$
W_{e, d}(a)=\max _{d^{\prime}}\left\{W_{e, d}^{d}(a)\right\}
$$

We can now write the problem of an household conditional to not changing dwelling as

$$
W_{e, d}^{d}(a)=\max _{y} u_{d}(c)+\pi \beta E\left\{V_{e^{\prime}, d}(y) / e\right\} \quad \text { subject to: } \quad c+p_{l} y=a,
$$

while that of an household that trades dwellings is

$W_{e, d}^{d^{\prime}}(a)=\max _{y} u_{d^{\prime}}(c)+\pi \beta E\left\{V_{e^{\prime}, d^{\prime}}(y) / e\right\} \quad$ subject to: $\quad c+p_{l} y-\phi\left(d, d^{\prime}\right)=a$,

Stationary Equilibrium To describe this economy at a point in time (a set of initial conditions) we need a distribution of households over dwellings, assets, and earnings shocks, $x$ defined over those variables. A stationary equilibrium is a specific distribution of households $x^{*}$ together with a set of asset prices $\left\{p_{\ell}^{*}, p_{f}^{*}, p_{h}^{*}\right\}$ such that when the distribution of households is given by $x *$ and the households face constant 
prices forever given by $\left\{p_{\ell}^{*}, p_{f}^{*}, p_{h}^{*}\right\}$ then their choices $(i)$ induce a distribution of households next period that is again $x^{*}$, and (ii) prices clear assets markets, that is

$$
\int_{e, d, y} y d x=1, \quad \int_{e, f, y} d x=\mu_{f}, \quad \int_{e, h, y} d x=\mu_{h} .
$$

\section{Mapping the Model to the data}

To specify the model we have to choose some parameters and functional forms. Some details of the specification of the model are independent of the equilibrium and can be set beforehand. The equilibrium allocation depends on the parameter choices and our aim is to set parameter values so some statistics in the model economy have certain desired values, typically the same as their counterpart in the data. The process of parameter selection can be referred either as a calibration or as a method of moments estimator, depending on the scholar. We first describe the specification and then the targets.

\subsection{Description of parameters}

Parameters that can be set independently The parameters that can be include population turnover features, $1.5 \%$ per year, and 67 years of average adult life (which sets $\pi=0.985$ ); we also set ex ante some features of the financial system such as a 1.\% mortgage premium, this is borrowing rate minus lending rate, a 20.\% down payment and 
a 10.\% cost of buying a dwelling, as a stand in for real estate commissions, taxes, and the time and hassle for the households involved in the purchase of the dwelling.

Preferences (3) Preferences are time separable with discount rate $\beta$ and a standard CRRA per period utility function with risk aversion parameter $\sigma=2$ (one of those parameters that is hard to pin down) and utility shifters $\gamma^{d}$ (two of them).

$$
u_{d}(c)=\frac{c^{1-\sigma}}{1-\sigma} \gamma^{d}
$$

Earnings Shocks (11) We choose an earnings process with three earnings classes and within each earnings class there is an interval of earnings with the continuous density $F(\epsilon, e)$ above. This gives 5 parameters for the intervals of earnings (one is normalization), 4 possible parameters of the transition matrix $\Gamma_{e, e^{\prime}}$ since we assume zero the probabilities of going from the top group to the bottom group and vice-versa and the additional parameter $\chi$ that adds flexibility to vary the mean to median ratio within each earnings class. To achieve a life cycle earnings profile where households increase their earnings on average over time, we assume that all households are born as poor. In models without housing there is a lot of work to estimate these parameters (see for example Castañeda, Díaz-Giménez and Ríos-Rull (1998) and Díaz, Pijoan-Mas and Ríos-Rull (2003)), and in this paper we use a process quite similar 
to that in the latter paper.

Asset parameters (3) While we normalize the size of the Lucas tree to 1 , the size of its dividend $d$ has to be specified. Also the number of flats $\mu^{f}$ and the number of houses $\mu^{h}$ relative to the population has to be set.

\subsection{Description of Targets/Moments to match}

1. We target a labor share out of income of 0.84 . Note that the absence of depreciation in our model makes the labor share larger.

2. Average earnings of those aged $31-60$ to those aged $20-30 ; 1.82$.

3. Financial asset wealth relative to income: 2.18 .

4. Owner occupied housing wealth times relative to income: 2.3 .

5. Fraction of households that own a house: 0.35 .

6. Fraction of people with flat: 0.30

7. House prices relative to flat prices $\frac{p_{h}}{p_{f}}: 2.0$.

8. Risk free interest rate of $5 \%$.

9. Down payment the first time a household buys a dwelling: $16.3 \%$.

10. Down payment of repeated buyers $26.5 \%$.

11. Ratio of mortgage debt to income of $34 \%$. 
12. Fraction of people with debt in the model (those who have negative financial assets is $40 . \%$.

13. Average ratio of financial debt to housing value is $50 \%$. This number has been increasing in the last few years and our target is appropriate for the early nineties.

14. General Properties of the Lorenz Curve of earnings.

15. General Properties of the Lorenz Curve of assets.

\subsection{Performance of the model economy}

The model does in general quite well in matching our targets despite having 17 parameters for 12 specific targets plus the general properties of the Lorenz curves. Moreover, of those 17 parameters there are 4 that play little role (3 that define the bounds of the earning classes and the parameter $\chi$ that governs the curvature of the density of earnings within each earning class. The actual values of the model statistics relative to our targets are $18 . \%$ for the down payment at first buy and $27.9 \%$ for at all purchases. The ratio of mortgages to income is $33.2 \%$. Also the actual fraction of people with debt is $41.6 \%$ and the the average ration of debt to housing value is $56.5 \%$. The interest rate in the economy is a little bit too high, $7 \%$.

Tables 1 and 2 shows selected statistics from the Lorenz curves for 
earnings and for wealth in both the model and data (as reported by ?)). We think that they are close enough given the degrees of freedom that we operate with.

Table 1: The Distribution of Earnings: Model and Data (1998 SCF)

\begin{tabular}{lccccccc}
\hline \hline & \multicolumn{5}{c}{ Quintiles } & & Gini \\
& 1st & 2nd & 3rd & 4th & 5 th & \\
\hline Model Earnings Share & 3.5 & v5.0 & v7.7 & 11.1 & 72.3 & .65 \\
Data Earnings Share & -0.2 & 4.0 & 13.0 & 22.9 & 60.2 & .61 \\
\hline \hline
\end{tabular}

\section{Conclusion and a Preview of Aggregate Uncertainty}

In this paper we have set the main building blocks to study housing prices in an economy where they are actively traded and that captures some of the important features of a modern economy with respect to what houses are. The next step is to study versions of this economy with aggregate uncertainty, on earnings, interest rates (dividends) mortgage premia, demoraphics and so on . The problem is that the state space includes the distribution of households across financial wealth, dwellings and earnings class. To avoid this problem we are using the approach pioneered by Krusell and Smith (1998) using the aggregate shocks and 
Table 2: Total, Financial and Housing Wealth Distribution

\begin{tabular}{lccccccc}
\hline & & 1st & 2nd & 3rd & 4th & 5th & Gini \\
\hline Total & Model & 0.24 & 1.30 & 2.27 & 9.92 & 86.27 & .82 \\
& US Eco & -0.29 & 1.35 & 5.14 & 12.37 & 81.43 & .80 \\
\hline \multirow{2}{*}{ Finan } & Model & -22.34 & -17.43 & -1.39 & 2.33 & 138.83 & 1.568 \\
& US Eco & -9.53 & -1.07 & 0.36 & 5.84 & 104.39 & 0.953 \\
\hline \multirow{2}{*}{ Housing } & Model & 0.00 & 5.69 & 20.92 & 31.56 & 41.84 & 0.457 \\
& US Eco & 0.22 & 2.92 & 12.78 & 22.45 & 61.63 & 0.626 \\
\hline
\end{tabular}

the current market clearing prices as the only state variables. This approach seems to be working and we will soon be able to report the stochastic properties of housing and equity prices.

\section{Appendix A: Parameter Values}

Preferences The preference parameters are $\beta=0.892127$, while the utility modifiers are $\gamma^{f}=0.19215$ and $\gamma^{d}=0.0637$.

Earnings process We chose three earnings classes with earnings in the intervals $\{[0.5,2.0],[1.5,12,5],[41.9,51.2]\}$ respectively, and with Transition Ma- 
trix

$$
\Gamma_{e e^{\prime}}=\left[\begin{array}{ccc}
0.992 & 0.008 & 0.000 \\
0.009 & 0.980 & 0.011 \\
0.000 & 0.083 & 0.917
\end{array}\right]
$$

The value of the parameter $\chi$ is 0.5 .

\section{Appendix B: Computational Procedures}

The problem that the households solve is very hard because it is not concave and first order conditions cannot be used to solve the model. Moreover, not only we have to solve the problem of the household and compute the stationary distribution for given parameters and prices, but we also have to do it many times to ensure that both the economy is in equilibrium (markets clear) and that the value of the model statistics are close to our targets.

There are three states in the household's problem: (i) financial assets, (ii) dwelling position and, (iii) earnings class and two decisions: savings, a continuous choice, and dwelling, that can take three values house, flat or nothing. This combination implies that in general the value function $W$ is not concave which means that the first order conditions are not sufficient to find the optimum. We tried to get around this problem by using continuous earnings realizations and taking expectations over the following period earnings (and thus defining 
function $V$ ) hoping that the kinks would be smoothed out. While this approach works very often, it does not work always (the earnings cannot be ensure to be spread enough so that the integration enforces concavity) which causes serious problems when the value function has to be solved many times as is the case when we are estimating parameters and even more in stochastic environments. Consequently we opted for the discretization of the state space, that is computationally very costly but also very robust. Still, we maintained the continuous support of earnings because the distribution of households and the decision rules oh households become smoother which makes for an easier estimation process. We use 700 points in the grid for the financial asset for function $V$ so there are 6300 possible individual states. The points in the grid are not equally spaced (they are closer for low values of wealth) and they are located in different locations for each dwelling. We then use successive approximations to find the solution to the household problem. Not that within each iteration the function $W$ has to be constructed, and the decision rules found. The distribution of households over assets and earnings class is a now a vector and can be easily stored. We have done our work in a powerful Beowulf cluster with 26 processors. 


\section{References}

[1] Aiyagari, S. Rao (1994), "Uninsured Idiosyncratic Risk and Aggregate Saving". Quarterly Journal of Economics 109: 659-684.

[2] Budría, Santiago, Díaz-Giménez, Javier, Ríos-Rull, José Víctor and Vincenzo Quadrini (2001), "Updated Facts on the U.S. Distributions of Earnings, Income, and Wealth ". Quarterly Review of the Federal Reserve Bank of Minneapolis 26:659-84.

[3] Castañeda, Ana, Díaz-Giménez, Javier and José V'ıctor Ríos-Rull (1998), " A general equilibrium analysis of progressive income taxation: qunatifying the trade-offs". University of Pennsylvania.

[4] Chambers, Matt, Garriga, Carlos and Don Schlagenhauf (2007), "Accounting for Changes in the Homeownership Rate". Mimeo.

[5] Díaz, Antonia and Luengo, M. José (2004), "Precautionary savings and wealth distribution with durables". Mimeo.

[6] Díaz, Antonia, Pijoan-Mas, Josep and José Víctor Ríos-Rull (2003), "Precautionary Savings and Wealth Distribution under Habit Formation Preferences". Journal of Monetary Economics, 50: 1257-1291.

[7] Diaz-Giménez, Javier and Luis Puch (1998), "Borrowing con- 
straints in economies with indivisible household capital and banking : an application to the spanish housing market (198289)". Investigaciones económicas, 22: 469-499.

[8] Gruber, Joseph.W and Robert.F. Martin (2003), "Does Housing Wealth Make Us Less Equal? The Role of Durable Goods in the Distribution of Wealth)". Mimeo.

[9] Heathcote, Jonathan and Morris Davis (2005), "The Price and Quantity of Residential Land in the United States".Mimeo

[10] Krussel, Per and Anthony Smith (1997), "Income and wealth heterogeneity, portfolio choice and equilibrium asset returns". Macroeconomic Dynamics, 1(2):387-422.

[11] Krussel, Per and Anthony Smith (1998), "Income and wealth heterogeneityin the macroeconomy". Journal of Political Economy, 106:867-896.

[12] Martin, Robert.F. (2005), "The baby boom: predictability in house prices and interest rates". Mimeo.

[13] Nakajima, Makoto (2005), "Rising earnings instability, porfolio choice and housing prices". Mimeo.

[14] Ortalo-Magne, Francois and Sven Rady (2006), "Housing Market Dynamics: On the Contribution of Income Shocks and Credit 
Constraints". The Review of Economic Studies, 73:459-485. 